\title{
Optimizing Cold Compression Deformation to Remove Residual Stresses in Die Forged Disc of Al-Mg-Si Alloy
}

\author{
NAVEED Akhtar ${ }^{a,{ }^{*}}$, MUHAMMAD Afzal ${ }^{\mathrm{b}}$, \\ MUHAMMAD Awais ${ }^{c}$ and MUHAMMAD Akbar ${ }^{d}$ \\ NINVAST, NCP Complex, Quaid-e-Azam University, Islamabad-Pakistan \\ a*naveed3158@gmail.com, bafzalmaz@gmail.com, cawais09uet@gmail.com, \\ dengrmuhdakbar@gmail.com
}

\begin{abstract}
Keywords: Residual Stresses, Aluminum Alloy, Close Die Forging, Cold Compression,
\end{abstract} Dimensional Stability

\begin{abstract}
Quenching residual stresses in Al-Mg-Si alloy forged disc were balanced via cold deformation compression method. In this experiment firstly, the forged disc of $\Phi 210 \times 52 \mathrm{~mm}$ was prepared from extruded stock material of $\Phi 160 \times 90 \mathrm{~mm}$ through close die forging technique. Next, the forged discs were quenched in water and cold compressed immediately. Finally, the discs were artificial aged to finish in T652 temper. Close die forging and cold compression deformation was performed on a 1200 Ton hydraulic forging press. The amount of cold compression deformation was varied from 2.0 to $5.0 \%$ to gauge the optimum level of cold compression for the removal of quenching residual stresses. The residual stresses were measured in terms of dimensional stability of the machined component. Results showed that the 3.8\% cold compression deformation was the optimized value for the work piece geometry under investigation. Further, the effect of cold (room temperature) and hot water $\left(\sim 60{ }^{\circ} \mathrm{C}\right)$ quenching on the residual stresses was also studied and compared with that of cold compression method.
\end{abstract}

\section{Introduction}

Residual stresses in metallic materials likely to cause permanent distortions in machined components. And, the finished components may not qualify the acceptable dimensional tolerance limits. Thus, it may affect the process yield and process economy at the same time. Residual stresses develop due to non-uniform cooling during rapid quenching of thicker parts $[1,2]$. The material gets cool rapidly from outside and start contracting, and the interior part of the material plastically deforms that is at higher temperature initially. After reasonable time interior part of material gets cool and want to contract, however, outer material resist this phenomenon [3]. In the whole process compressive stresses will develop in the outer region of the work piece, while tensile stresses in the inner region. These tensile and compressive stresses are present in a balance state inside the as-quenched material. Machining process disturbs this stress balance and the component face a distortion after machining of the part [4], and the final dimensions do not meet the acceptable criteria.

It has been well documented [2-4] that quenching residual stresses increases with increasing plate thickness, and may reach as-quenched yield strength in plates of very large thickness. The reason behind is the quench non-uniformity with increasing thickness of the work piece. Research $[2,5-8]$ has been done to study the various contributing factoring such as quenching media, temperature of the quenching media, geometry and thickness of the work piece, heat treatment procedure and temperature, machining parameters and depth of machining [9, 10]. These factors contribute differently towards the peak magnitude of the compressive and tensile stresses in the material. Researchers have explored a number of techniques to remove quenching residual stresses for minimizing distortions in the machined components. However, it may involve a number of variables, and each technique has certain limitations. Previous studies [11-14] have been done in the following three directions to counter the residual stresses in aluminum alloys: 
1) By using warm water as a quenching media; it reduces thermal gradients in the material during the quenching process, although it may decrease the strength as well.

2) By applying controlled cold compression or stretching $[15,16]$ followed by the quenching and before the ageing of the parts.

3) By thermal stress relieving [17,18] (artificial ageing at low temperatures for longer periods may reduce residual stresses up to certain level).

In this study we have tried to remove or minimize the quenching residual stresses by applying cold compression deformation (mechanical stress leveling technique). We applied 2.0 to $5.0 \%$ cold compression deformation immediately after the water quenching of the die forged discs. The optimum level of cold compression amount was found by increasing the cold compression in the order of 0.5 degree from 2.0 to $5.0 \%$. Two batches having 7 specimens each were also studied without cold deformation; one batch was quenched in warm water, while the other in normal water at room temperature.

\section{Experimental Procedure}

Material and Processing. The chemical composition (wt.\%) of the aluminum alloy (AA6061) was as follow: $\mathrm{Si} 0.66, \mathrm{Mg} \mathrm{0.90,} \mathrm{Fe} \mathrm{0.21,} \mathrm{Cu} \mathrm{0.26,} \mathrm{Cr} \mathrm{0.18,} \mathrm{Ti} 0.01$ and balanced with Al. First of all, the alloy was cast into solid billet $\Phi 460 \mathrm{~mm}$ via direct chill (DC) casting process. The homogenized billet was machined to get $\Phi 450 \mathrm{~mm}$, and subsequently extruded to form rod of $\Phi$ $160 \mathrm{~mm}$. The extruded rod was used as a stock material for close die forging process. The dimension of the stock billet for forging was $\Phi 160$ x $90 \mathrm{~mm}$. Further, the material was processed via close die forging to obtain a disc of $\Phi 210 \times 52 \mathrm{~mm}$; the process parameters used are listed in Table 1 . Hydraulic forging press of 1200 Ton capacity was used in this study. Afterwards, the discs were solution treated by using normal water as well as hot water $\left(60^{\circ} \mathrm{C}\right)$ as a quenching media. Immediately, followed by the quenching the discs were cold compressed in the range of 2.0 to $5.0 \%$ permanent set. Finally, the cold compressed discs were age heat treated to get T652 temper. The schematic of the close die forging process is shown in Fig. 1.

Table 1. Parameters used for die forging, cold compression and heat treatment.

\begin{tabular}{|c|c|}
\hline Parameter / Variables & Value \\
\hline \multicolumn{2}{|l|}{ Forging } \\
\hline Stock size, $\mathrm{mm}$ & $\Phi 160 \times 90$ \\
\hline Billet temperature, ${ }^{\circ} \mathrm{C}$ & 450 \\
\hline Soaking time, hour & 2.0 \\
\hline Die pre-heating temperature, ${ }^{\circ} \mathrm{C}$ & $150-200$ \\
\hline Forging speed, $\mathrm{mm} / \mathrm{s}$ & 7.9 \\
\hline Forging load, Ton & 800 \\
\hline Load holding time, $\mathrm{s}$ & $0-1$ \\
\hline \multicolumn{2}{|l|}{ Cold Compression } \\
\hline Delay time after quenching, min & $15-60$ \\
\hline Deformation, $\%$ & $2.0-5.0$ \\
\hline \multicolumn{2}{|l|}{ Heat treatment } \\
\hline Solutionizing temperature, ${ }^{\circ} \mathrm{C}$ & $530(80$ min hold $)$ \\
\hline Ageing temperature, ${ }^{\circ} \mathrm{C}$ & 170 (08 hrs hold) \\
\hline
\end{tabular}




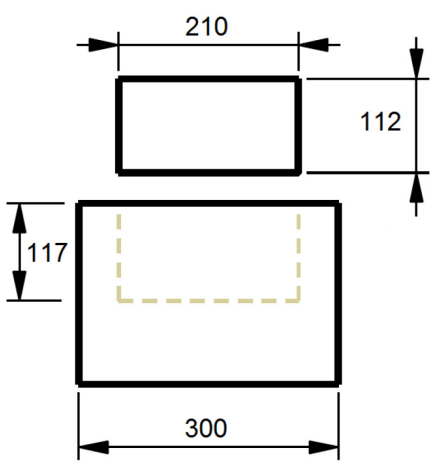

(a)

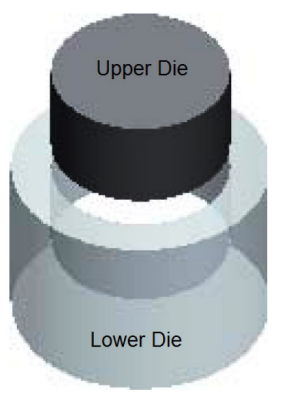

(b)

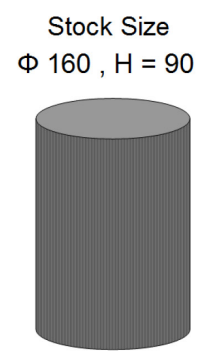

(c)

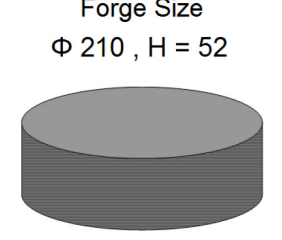

Fig. 1. Schematic of close die forging, (a) punch and hollow die, (b) stock size, (c) forged disc.

Microstructure and Mechanical Properties. The metallographic and tensile specimens were sectioned in transverse direction through mid-thickness from the forged disc after T652 temper. In order to study the microstructure, the specimens were ground well by using abrasive paper up to 3000 grit, and then mechanically polished by using $1.0 \mu \mathrm{m}$ alumina suspension. Finally, the specimens were chemically etched with Keller's solution and examined under the optical and scanning electron microscope.

Mechanical properties were studied by using standard $12.5 \mathrm{~mm}$ round tension test specimen with $62.5 \mathrm{~mm}$ gauge length. Five tensile test specimen of each state such as normal water quenched, hot water quenched, and cold compressed (deformation 2.0 to $5.0 \%$ with an increment of $0.5 \%$ ) was tested on $100 \mathrm{kN}$ machine. The test specimens were cut through the transverse direction of the disc.

Residual Stresses and Distortion. There are many methods to measure the residual stresses in components mentioned elsewhere [19]. We studied the residual stress and distortion in terms of dimensional variation in the size of the component after 48 hours of machining operations. The schematic of the component for dimension stability test has been shown in Fig 2. The dimension measurement was taken with the help of coordinate measuring machine. A minimum of three representative specimens of each category was taken, and the results quoted are mean value of 4 readings made on each component at different places.
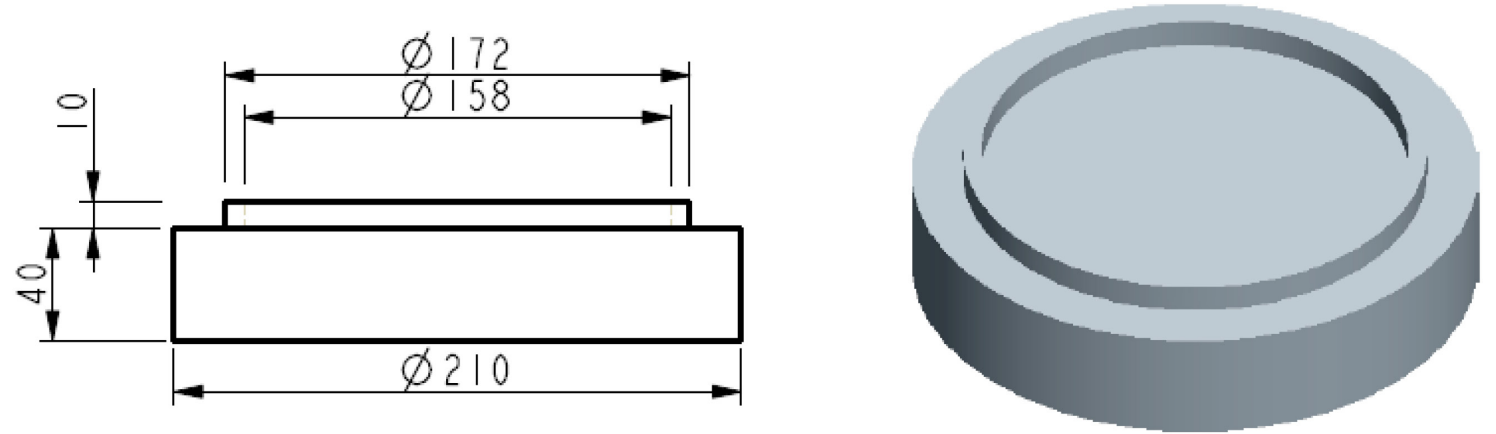

Fig. 2. Schematic of the die forged disc used for dimensional stability test.

\section{Results and Discussion}

Microstructure. Fig. 3 presents the microstructure of the DC cast billet in as-cast and homogenized condition. From the Fig. 3 it is obvious that homogenization heat treatment of the cast billet at $570{ }^{\circ} \mathrm{C}$ for 6 hours successfully dissolved the coarse $\mathrm{Mg}_{2} \mathrm{Si}$ particles, transformed the $\beta$-AlFeSi phase to $\alpha$-AlFeSi phase, and dispersed the light alloying elements homogenously within the grains. The as-cast and homogenized microstructure shown in Fig. 3 is typical and characteristic of Al-MgSi alloy family. The homogenized billet was further extruded into rod of $\Phi 160 \mathrm{~mm}$ on a direct extrusion press. The extrusion process broken the cast structure and a freshly developed elongated grain structure in the extrusion direction was evolved. The extruded rod was cut into $\Phi 160 \mathrm{x}$ $90 \mathrm{~mm}$ and used as a stock material for the close die forging. The microstructure of die forged disc 
in T6 temper has been given in Fig. 4. It is typically forged grain structure of equiaxed morphology (Fig. 4a). It was observed that hot deformation during the die forging process produced the characteristics forged microstructure. The elongated grains of stock material (extruded grain structure) were transformed into compact grain structure. Moreover, intermetallic particles aligned themselves along the gain boundaries in the direction of flow during hot deformation process (Fig. $4 \mathrm{~b})$. The microstructure analysis showed that fine grains of 50-800 $\mu \mathrm{m}$ were present in the center of the disc, whereas 1-3 mm large grains in the outer peripheries (Fig. 5).

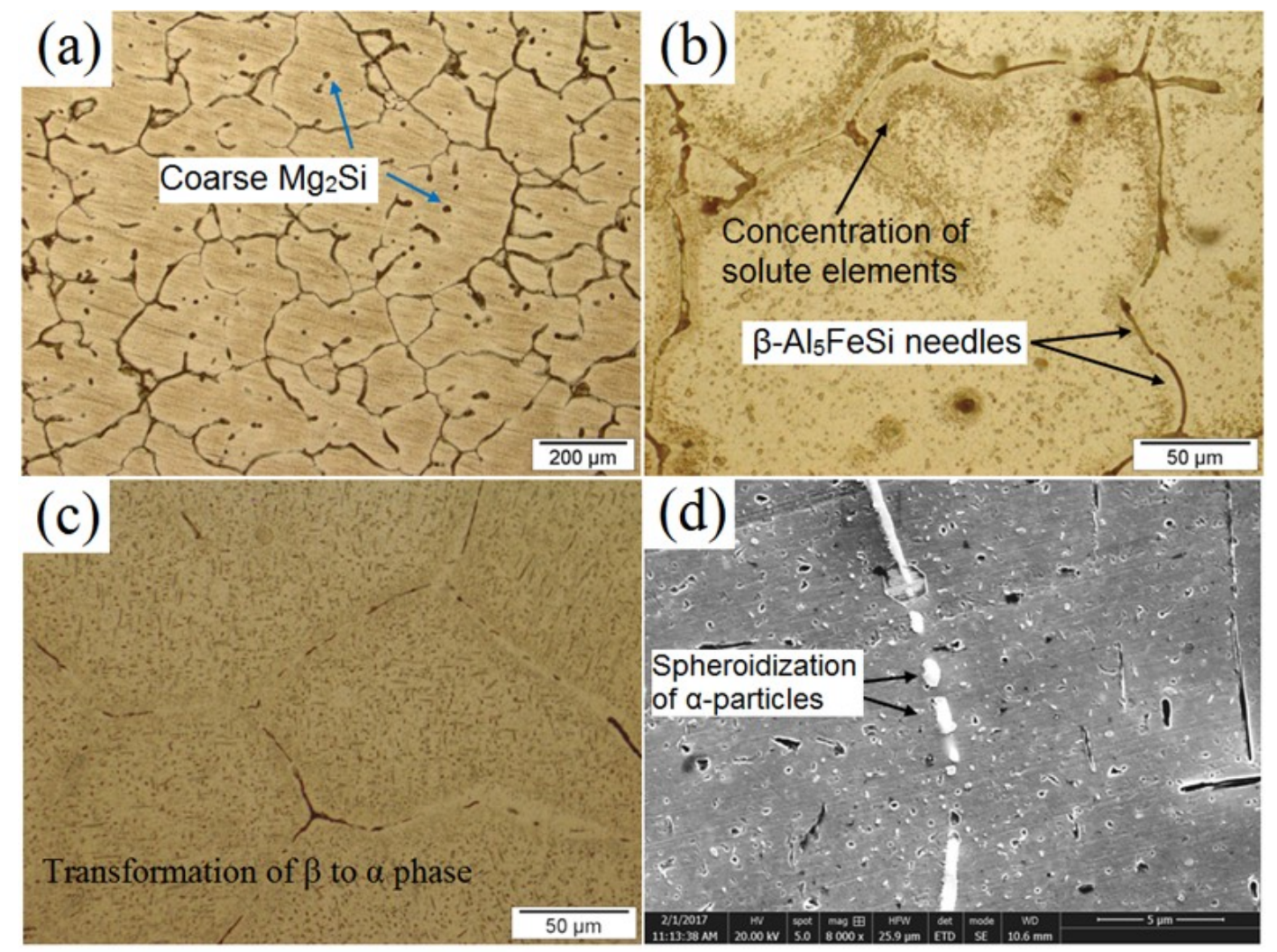

Fig. 3. (a) As-cast microstructure of $\mathrm{DC}$ cast billet showing dendrite grain boundaries and coarse $\mathrm{Mg}_{2} \mathrm{Si}$ particles, (b) concentration of light solute elements near the grain boundaries in as-cast billet, (c) homogenized structure showing the transformation of $\beta-\mathrm{Al}_{5} \mathrm{FeSi}$ to $\alpha-\mathrm{Al}_{12} \mathrm{Fe}_{3} \mathrm{Si}$, (d) needle shape $\beta$ phase transformed into small spheroid and plate like fragments of $\alpha-\mathrm{Al}_{12} \mathrm{Fe}_{3} \mathrm{Si}$.

Mechanical Strength. The entire die forged specimens qualified the mechanical properties such as tensile strength, yield strength and hardness. The graph given in Fig. 6 showed that the tensile strength and the elongation did not show any correlations with the amount of cold compression deformation, and both the parameters varied independently. On the other hand, the yield strength showed a liner relationship with the amount of cold compression deformation as shown in the Fig.6.

Fig. 7 presents the SEM fractographs of tensile test specimen. From the figure it is obvious that the fracture was purely ductile in nature. The dimple appearance on the fracture surface is formed as a result of void coalescence mechanism during the uniaxial tensile loading. Initially, micro voids developed around the intermetallic particles and secondary phases of the Al-Mg-Si alloy. These micro voids coalesce together to form micro-cracks and led to the material failure. 


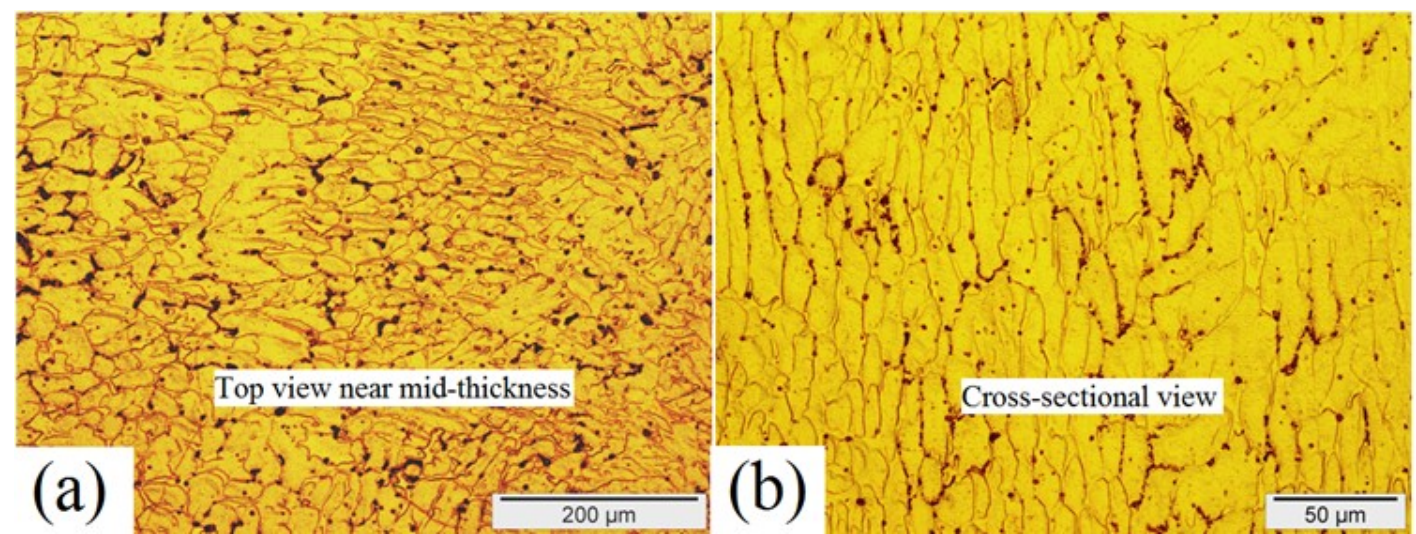

Fig. 4. Optical micrographs of die forged specimen H3 (hot water quenched and $0 \%$ cold compression), (a) grain structure in the center of the disc, (b) grain structure as viewed in cross-section of the disc. Specimens were etched in Keller's solution.
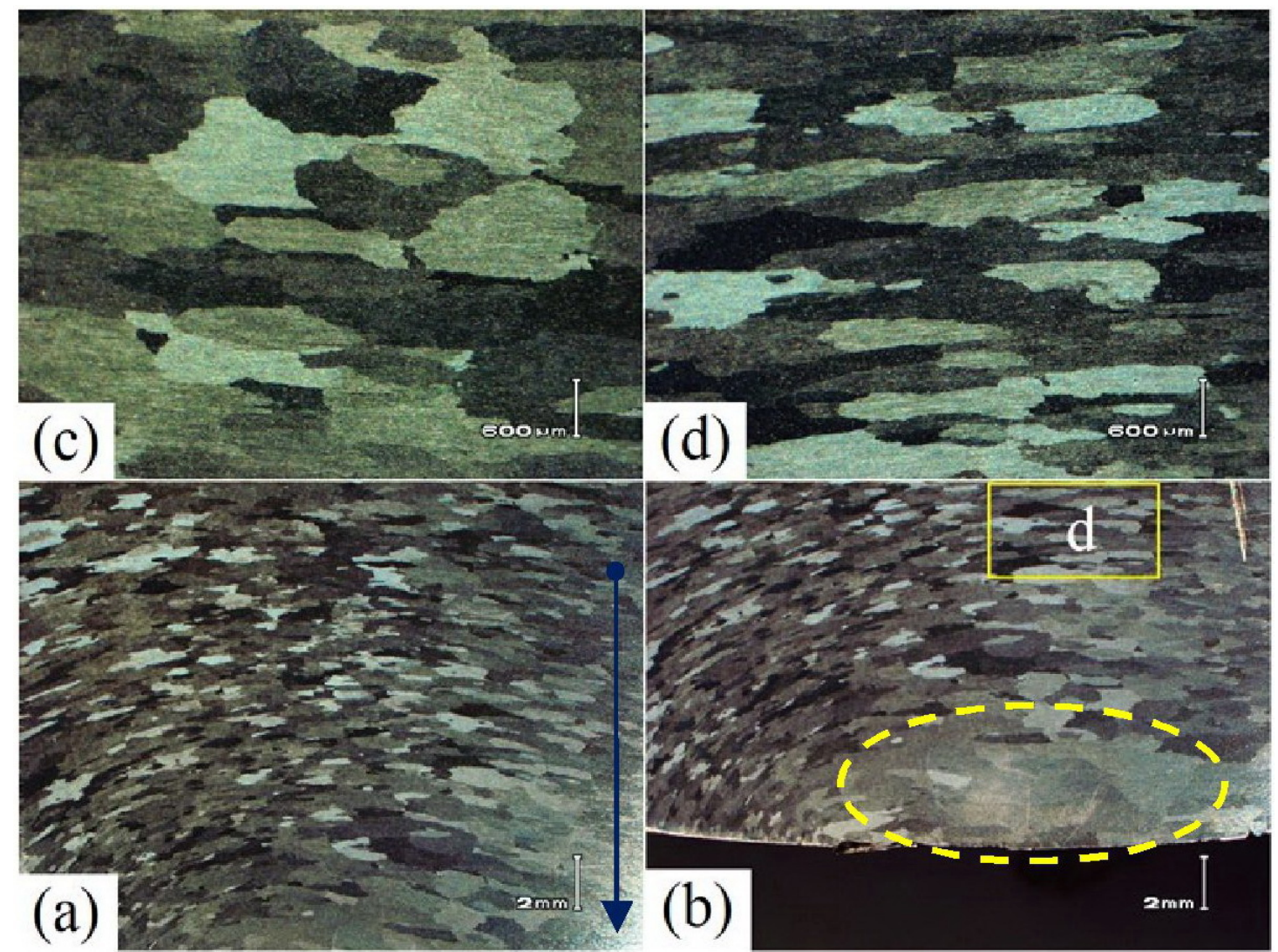

Fig. 5. Stereo micrographs of die forged specimen T38 (3.8\% cold compression), (a) grain structure as viewed in long-transverse direction; arrow head pointing towards outer edge, (b) large grains in the outer peripheries of the disc are highlighted in circle (c) equiaxed grain structure towards the center of the disc. Specimens were etched in $1 \%$ HF solution.

Dimensional stability. Fig. 8 presents the size variation after $48 \mathrm{hrs}$ of machining operations from the acceptable size tolerance limits. The specimens from $\mathrm{C} 1$ to $\mathrm{C} 7$ were quenched in normal water at room temperature and age heat treated without any cold compression. These seven specimens showed the largest deviation from the acceptable limit and deviation was found in the range of +37 to $+57 \mu \mathrm{m}$ after $48 \mathrm{hrs}$ of machining. Machining distortion was improved $>38 \%$ when the die forged discs were quenched in warm water with an average size deviation of $+0.29 \mu \mathrm{m}$. However, still the size deviations do not fall into the permissible limits. 


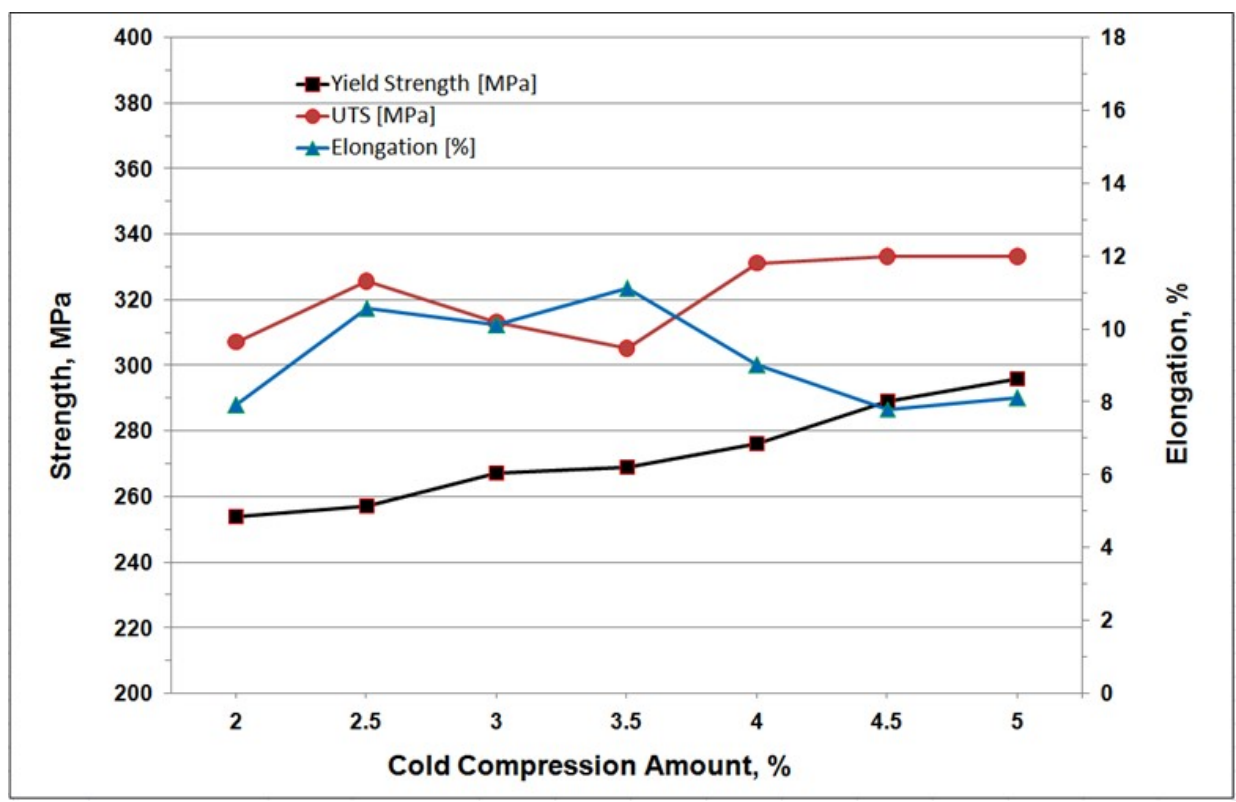

Fig. 6. Effect of cold compression deformation on the mechanical properties of die forged disc.

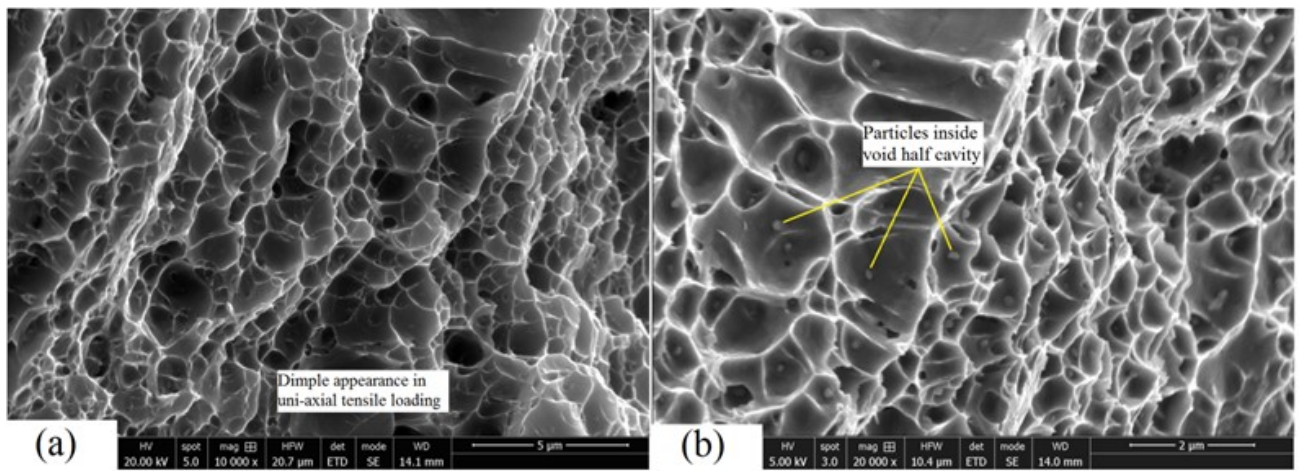

Fig. 7. SEM micrographs of fracture surface of tensile test specimen T38.

The specimens from $\mathrm{T} 1$ to $\mathrm{T} 7$ were cold compressed $\sim 2.0 \%$, which showed a size deviation from -40 to $+37 \mu \mathrm{m}$. By increasing the cold compression amount gradually in the order of $0.5 \%$ increment, it was observed that most of the specimen qualified the dimensional criteria when cold compressed 3.5 to $4.0 \%$. Though, $4.0 \%$ cold compression produced size deviation on negative side. It is obvious from this fact that the optimized cold compression point for the work piece geometry to remove the maximum quenching residual stress would be in-between the $3.5 \%$ and $4.0 \%$. Hence, a set of seven specimens were cold upset at 3.8\% value immediately followed by the quenching. The size deviation ranged -7.0 to $+6.0 \mu \mathrm{m}$ and fall within the acceptable tolerance limits, as shown in Fig. 8 by doted ring. This is $>85 \%$ decrease in size variation when compared to the maximum deviation observed in specimens without cold compression and quenched in normal water.

Fig. 9 presents the histogram (bottom) and the probability graph (top) of size deviation in all the specimens processed via cold deformation technique to balance the quenching residual stresses. It is obvious from the histogram that the frequency of size deviation towards negative side is greater than the positive size. The possible reason behind this trend might be the fixed forging load value (set at $800 \mathrm{~T}$ ). The cold compression was performed by placing the disc between the flat dies without any fixture to control the height of the disc during the cold upsetting process. 


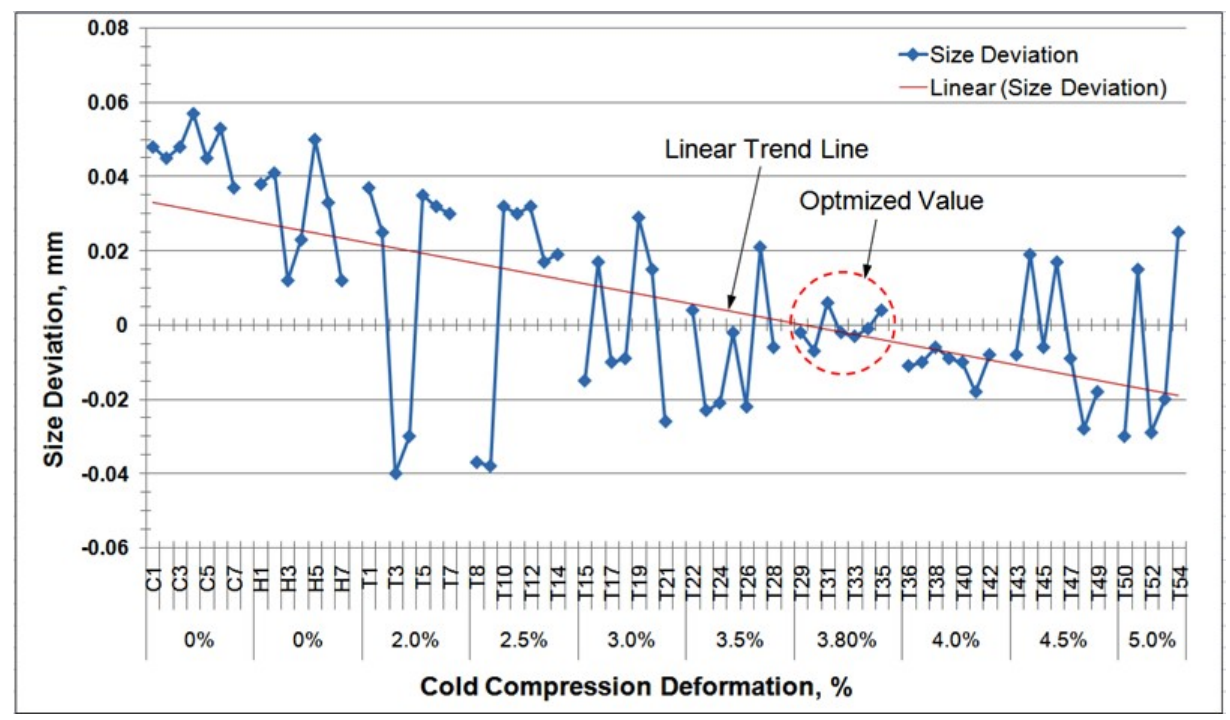

Fig. 8. Effect of cold compression amount on the dimension stability of the die forged discs.

The probability distribution graph showed that the cold compression deformation had balanced quenching stresses in $70 \%$ of the specimens that fall within the range of $\pm 10 \mu \mathrm{m}$.

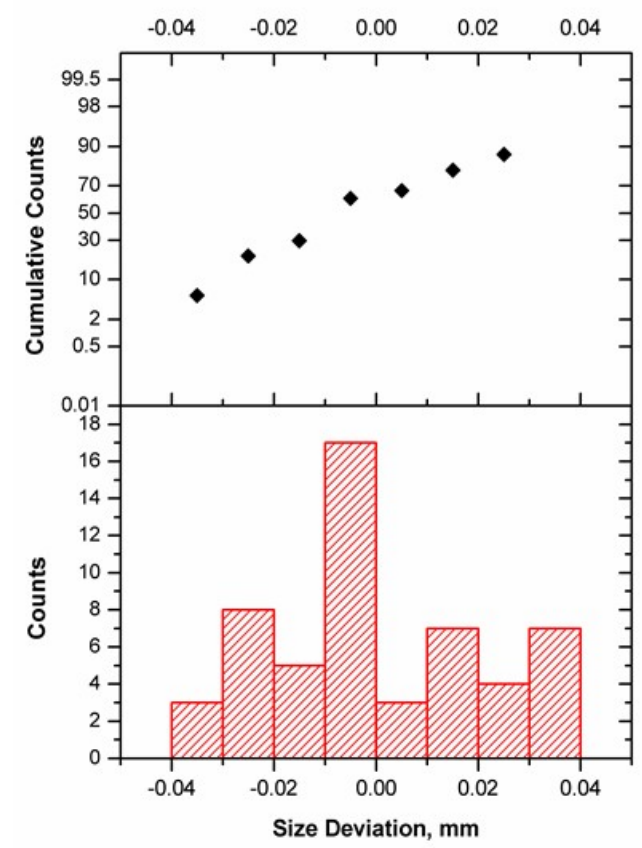

Fig. 9. Histogram and the normal probability graph of size deviation in cold compressed discs.

\section{Summary}

The experimental results and above made discussion conclude that the application of $3.8 \%$ cold compression deformation produced minimum distortions after 48 hours of machining operations. Based on size deviation and probability distribution 3.8\% cold compression amount was found optimum for the experimental work-piece of Al-Mg-Si alloy. This much amount of cold compression is necessary to level maximum quenching residual stresses of the die forged disc. Further, it was found that by increasing the cold compression deformation beyond the $4.0 \%$ the magnitude of the residual stresses in the disc also increases which translated into greater size deviation. 


\section{References}

[1] D. Thompson, B. Subramanya, S. Levy, Quench rate effects in Al-Zn-Mg-Cu alloys, Metallurg. Mater. Trans. B, 2 (1971) 1149-1160.

[2] D. Tanner, J. Robinson, Residual stress magnitudes and related properties in quenched aluminium alloys, Mater. Sci. Technol., 22 (2006) 77-85.

[3] B. Shang, Z. Yin, G. Wang, B. Liu, Z. Huang, Investigation of quench sensitivity and transformation kinetics during isothermal treatment in 6082 aluminum alloy, Mater. Des., 32 (2011) 3818-3822.

[4] E. Brinksmeier, J. Cammett, W. König, P. Leskovar, J. Peters, H. Tönshoff, Residual stressesmeasurement and causes in machining processes, CIRP Annals-Manufact. Technol., 31 (1982) 491510.

[5] J. Robinson, D. Tanner, C. Truman, A. Paradowska, R. Wimpory, The influence of quench sensitivity on residual stresses in the aluminium alloys 7010 and 7075, Mater. Character., 65 (2012) 73-85.

[6] J. Robinson, S. Hossain, C. Truman, A. Paradowska, D.J. Hughes, R. Wimpory, M. Fox, Residual stress in 7449 aluminium alloy forgings, Mater. Sci. Eng.: A, 527 (2010) 2603-2612.

[7] G. Dolan, J. Robinson, Residual stress reduction in 7175-T73, 6061-T6 and 2017A-T4 aluminium alloys using quench factor analysis, J. Mater. Proces. Technol., 153 (2004) 346-351.

[8] S. Liu, Q. Zhong, Y. Zhang, W. Liu, X. Zhang, Y. Deng, Investigation of quench sensitivity of high strength $\mathrm{Al}-\mathrm{Zn}-\mathrm{Mg}-\mathrm{Cu}$ alloys by time-temperature-properties diagrams, Mater. Des., 31 (2010) 3116-3120.

[9] J.S. Robinson, D.A. Tanner, C. Truman, R. Wimpory, Measurement and prediction of machining induced redistribution of residual stress in the aluminium alloy 7449, Experi. Mech., 51 (2011) 981-993.

[10] B. Denkena, D. Boehnke, L. De Leon, Machining induced residual stress in structural aluminum parts, Prod. Eng., 2 (2008) 247-253.

[11] M.B. Prime, M.R. Hill, Residual stress, stress relief, and inhomogeneity in aluminum plate, Scr. Materi.a, 46 (2002) 77-82.

[12] D.A. Tanner, J.S. Robinson, R.L. Cudd, Cold compression residual stress reduction in aluminium alloy 7010, in: Materials science forum, Trans. Tech. Publ., 2000, pp. 235-240.

[13] D.A. Lados, D. Apelian, L. Wang, Minimization of residual stress in heat-treated Al-Si-Mg cast alloys using uphill quenching: Mechanisms and effects on static and dynamic properties, Mater. Sci. Eng.: A, 527 (2010) 3159-3165.

[14] D. Tanner, J. Robinson, Reducing residual stress in 2014 aluminium alloy die forgings, Mater. Des., 29 (2008) 1489-1496.

[15] M. Koc, J. Culp, T. Altan, Prediction of residual stresses in quenched aluminum blocks and their reduction through cold working processes, J. Mater. Proc. Technol., 174 (2006) 342-354.

[16] D. Tanner, J. Robinson, Modelling stress reduction techniques of cold compression and stretching in wrought aluminium alloy products, Fini. Elem. Anal. Des., 39 (2003) 369-386.

[17] J. Robinson, D. Tanner, Residual stress development and relief in high strength aluminium alloys using standard and retrogression thermal treatments, Mater. Sci. Technol., 19 (2003) 512-518.

[18] J. Robinson, D. Tanner, Reducing residual stress in 7050 aluminum alloy die forgings by heat treatment, J.Eng. Mater. Technol., 130 (2008) 031003.

[19] N. Rossini, M. Dassisti, K. Benyounis, A.G. Olabi, Methods of measuring residual stresses in components, Mater. Des., 35 (2012) 572-588. 